\title{
Clostridium tetani IgG Antibody Measurement
}

National Cancer Institute

\section{Source}

National Cancer Institute. Clostridium tetani Ig G Antibody Measurement. NCI Thesaurus.

Code C103382.

The determination of the amount of the Clostridium tetani IgG antibody in a sample. 